\title{
The influence of dietary factors on the incidence of ovarian cancer in women
}

\author{
Jie Gao* \\ Department of Obstetrics and Gynecology, Baogang Hospital, Baotou, Inner Mongolia, China
}

Received: March 17, 2018

DOI: $10.14725 /$ dcc.v5n2p11

\author{
Accepted: April 28, $2018 \quad$ Online Published: June 10, 2018 \\ URL: http://dx.doi.org/10.14725/dcc.v5n2p11
}

\begin{abstract}
The mortality of ovarian cancer occupies the first place among all types of gynecological tumors, which poses a serious threat to women's lives. This study is intended to investigate the dietetic status of patients with ovarian cancer in Inner Mongolia through questionnaires.
\end{abstract}

Key Words: Ovarian cancer, Dietary factors

The incidence of ovarian cancer is only second to cervical cancer and endometrial carcinoma, but its mortality occupies the first place among all types of gynecological tumors. It poses a serious threat to women's lives. The cause of ovarian cancer is complicated. In addition to lifestyle, biological factors and genetic factors, environmental factors (such as various harmful substances in the environment) and dietary factors etc. have attach great importance to experts and scholars. According to some reports, $30 \%$ of male cancers and $60 \%$ of female cancers in developed countries may be related to food. ${ }^{[1,2]}$ The dietary structure in Inner Mongolia is different from other regions, furthermore, it has been found that the number of patients with ovarian cancer is increased significantly in recent years. Therefore, this study is intended to investigate the dietetic status of patients with ovarian cancer through questionnaires.

\section{Objects and methods}

\subsection{Research Objects}

111 cases of female patients hospitalized in the Third Affiliated Hospital of Inner Mongolia Medical College dur- ing January of 2009 to October of 2011 were chosen and included in this research. These patients, aged 20 to 65 years, have lived in Baotou of Inner Mongolia Autonomous Region for no less than 20 years. 47 patients out of the above-mentioned 111 patients got neither an operation nor radiotherapy and chemotherapy before hospitalization. After surgery, they were diagnosed as ovarian cancer by way of histopathological tests and included in the case group. Meanwhile, according to matched age and region, 64 patients without ovarian cancer were chosen from the same hospital and included in the control group. Exclusion criteria were listed as follows: patients less than 18 years old or more than 65 years old; patients in the gestation period or lactation period; patients with severe diseases in heart, liver, kidney and hematopoietic system.

\footnotetext{
*Correspondence: Jie Gao; E-mail: dcc71@ncspress.com; Address: Department of Obstetrics and Gynecology, Baogang Hospital, Baotou, Inner Mongolia, China.
} 
tents included: basic information (age, occupation, education background, body mass index, family monthly income, family history of cancer, marital status); female-related information (age at menarche, marriage age, childbearing age, methods of contraception, number of children born, feeding pattern, frequency of gynecological examination, exercise mode and frequency); dietetic status and eating habits.

\subsection{Statistical analysis}

The data were established after the survey results were confirmed, and SPSS 13.0, a statistical analysis software, was used to make an analysis of all data acquired. $\chi^{2}$ test was used as a statistical method, and the difference $(p<.05)$ was of statistical significance.

\section{Results}

\subsection{Comparison in eating habits between two groups}

In Table 1, there were almost no changes in the diet in the case group and the control group in the past 5 years, patients in these two groups had regular diet and same cooking methods, and the difference was not statistically significant $(p>$ $.05)$. The proportion of picky or partial eating in the control group was lower than that in the case group $(p<.05)$.

\subsection{Comparison in food intake between two groups}

Patients in the case group were more likely to eat high-fat, sweet and pickled foods, with no less than $150 \mathrm{~g}$ of meat consumption a day, and the proportion of those who often ate eggs was higher than that in the control group; patients in control group ate more than $450 \mathrm{~g}$ of vegetables every day, and the proportion of those who ate fruit and drink tea every day was higher than that in the case group (all $p<.05$ ). The differences in the intake of staple food, bean products and milk were of no statistical significance $(p>.05)$. The dietary intake of the two groups was shown in Table 2.

\section{Discussion}

It has been reported that dietary factors are associated with the occurrence of tumorigenesis. This study has found that there are some differences in eating habits and food intake between the control group and the case group. The proportion of patients who take in tea, light diet, vegetables and fruits in the control group is higher than that in the case group. Meanwhile, the proportion of patients who take in eggs, meat, sweet food, high-fat food, and pickled food is lower than that in the case group. The results in this paper show that regular drinking tea, eating more fruits and vegetables, eating less sweet food, meat, high-fat food and pickled food are probably protective factors to reduce the occurrence of tumors.

Table 1: Comparison in eating habits between two groups of subjects [n (\%)]

\begin{tabular}{|c|c|c|c|}
\hline Eating Habits & Control Group $(n=64)$ & Case Group $(n=47)$ & $p$ \\
\hline Dietary changes in past 5 years & & & $>.05$ \\
\hline - Yes & $59(92.2)$ & $46(97.9)$ & \\
\hline - No & $5(7.8)$ & $1(2.1)$ & \\
\hline Regular Diet & & & $>.05$ \\
\hline - Regular & $63(98.4)$ & $47(100.0)$ & \\
\hline - Irregular & $1(1.6)$ & 0 & \\
\hline Vegetable Cooking Method & & & $>.05$ \\
\hline - Cooked & $63(98.4)$ & $47(100.0)$ & \\
\hline - Raw & $1(1.6)$ & 0 & \\
\hline Picky or partial eating & & & $<.05$ \\
\hline - Yes & $7(10.9)$ & $13(27.6)$ & \\
\hline - No & $57(89.1)$ & $34(72.3)$ & \\
\hline Diet Type & & & $<.01$ \\
\hline - Light & $35(54.7)$ & $2(4.2)$ & \\
\hline - Moderate & $9(14.1)$ & $23(48.9)$ & \\
\hline - Oily & $20(31.2)$ & $22(46.8)$ & \\
\hline
\end{tabular}


Table 2: Comparison in food intake between two groups of subjects [n (\%)]

\begin{tabular}{|c|c|c|c|}
\hline Food Intake & Control Group $(n=64)$ & Case Group $(n=47)$ & $p$ \\
\hline High-fat Food Intake & & & $<.01$ \\
\hline - Never & $39(60.9)$ & $6(12.8)$ & \\
\hline - Occasionally & $24(37.5)$ & $24(51.1)$ & \\
\hline - Often & $1(1.6)$ & $17(36.2)$ & \\
\hline Meat Intake (g) & & & $<.01$ \\
\hline - $<150$ & $45(70.3)$ & $16(30.0)$ & \\
\hline - $150 \sim$ & $8(12.5)$ & $19(40.4)$ & \\
\hline - $300 \sim$ & $11(17.2)$ & $10(21.3)$ & \\
\hline - $\geq 450$ & 0 & $2(4.2)$ & \\
\hline Vegetable Intake (g) & & & $<.01$ \\
\hline - $<150$ & $4(6.2)$ & $7(14.9)$ & \\
\hline - $150 \sim$ & $7(10.9)$ & $20(42.6)$ & \\
\hline - $300 \sim$ & $15(23.4)$ & $13(27.6)$ & \\
\hline - $\geq 450$ & $38(59.4)$ & $7(14.9)$ & \\
\hline Fruit Intake & & & $<.05$ \\
\hline - Never & $1(1.6)$ & $5(10.6)$ & \\
\hline - Occasionally & $13(20.3)$ & $11(23.4)$ & \\
\hline - Often & $19(29.7)$ & $19(40.4)$ & \\
\hline - Daily & $31(48.4)$ & $12(25.5)$ & \\
\hline Bean Product Intake & & & $>.05$ \\
\hline - Never & $7(10.9)$ & $10(21.3)$ & \\
\hline - Occasionally & $31(48.4)$ & $25(53.2)$ & \\
\hline - Often & $26(40.6)$ & $12(25.5)$ & \\
\hline Staple Food Intake (g) & & & $>.05$ \\
\hline - $<150$ & $3(4.7)$ & $3(6.3)$ & \\
\hline - $150 \sim$ & $27(42.2)$ & $12(25.5)$ & \\
\hline - $300 \sim$ & $29(45.3)$ & $26(55.3)$ & \\
\hline - $\geq 450$ & $5(7.8)$ & $6(12.8)$ & \\
\hline Sweet Food Intake & & & $<.01$ \\
\hline - Never & $23(35.9)$ & 7 (14.9) & \\
\hline - Occasionally & $22(34.4)$ & $12(25.5)$ & \\
\hline - Often & 19 (29.7) & $28(59.6)$ & \\
\hline Tea Drinking & & & $<.01$ \\
\hline - Never & $36(56.2)$ & $38(80.8)$ & \\
\hline - Occasionally & 14 (21.9) & $7(14.9)$ & \\
\hline - Often & $14(21.9)$ & $1(2.1)$ & \\
\hline Pickled Food Intake & & & $<.05$ \\
\hline - Never & $20(31.2)$ & $6(12.8)$ & \\
\hline - Occasionally & $35(54.7)$ & $25(39.1)$ & \\
\hline - Often & $9(14.1)$ & $16(25)$ & \\
\hline Milk Drinking & & & $>.05$ \\
\hline - Never & $18(28.1)$ & $9(19.1)$ & \\
\hline - Occasionally & $26(40.6)$ & $18(38.3)$ & \\
\hline - Often & $20(31.2)$ & $20(42.5)$ & \\
\hline Egg Intake & & & $<.01$ \\
\hline - Never & $7(10.9)$ & $2(4.2)$ & \\
\hline - Occasionally & $29(45.3)$ & $6(12.8)$ & \\
\hline - Often & $26(40.6)$ & $37(78.7)$ & \\
\hline - Daily & $2(3.1)$ & $2(4.2)$ & \\
\hline
\end{tabular}


The anti-cancer mechanism of tea is mainly to block the synthesis of nitrosamine carcinogens, interfere with the activation of carcinogens in the human body and eliminate free radicals. Vegetables and fruits are abundant in mineral substances and vitamins, and they also contain flavonoids. Since the 1970s, it has been found that flavonoids have good anti-tumor effects, and many studies on their anti-tumor mechanisms have been conducted. It has been proved that one of the anti-tumor mechanisms of flavonoids is that they can promote the apoptosis of tumor cells. ${ }^{[3]}$ Larsson et al. ${ }^{[4]}$ have found that patients who eat more fruits and fresh vegetables have a low incidence of ovarian cancer and a significant dose-dependent relationship. Pan et al. ${ }^{[5]}$ have showed in their research that eating large quantities of cruciferous vegetables and taking vitamin $\mathrm{E}, \beta$-carotene, and compound vitamin $\mathrm{B}$ can reduce the risk of ovarian cancer, suggesting that plant-based diets can reduce the incidence of hormonedependent cancers.

In the researches conducted by David et al. ${ }^{[6]}$ and Armstrong et al., ${ }^{[7]}$ it has been found that the incidence and the morality of ovarian cancer are positively correlated to the

\section{References}

[1] Lang JH. Global challenges and oportunitics in cervical cancer prevention. Chinese Journal of Obstetrics and Gynecology. 2002; 37(2): 129-131.

[2] Ye TT. Preventive Medicine. Third Edition. Beijing: People's Medical Publishing House; 2000. 350 p.

[3] Huang HY, Cha XL. Current progress on the anti-cancer effect of flavonoes compounds. Chinese Journal of New Drugs and Clinical Remedies. 2002; 21(7): 428.

[4] Larsson SC, Holmberg L, Wolk A. Fruit and vegetable consumption in relation to ovarian cancer incidence: the Swedish mam mography cohort. Br J Cancer. 2004; 90(11): 2167-2170. PMid: 15150575. https://doi.org/10.1038/sj.bjc.6601872

[5] Pan SY, Ugnat AM, Mao Y, et al. A case control study of diet and the risk of ovarian cancer. Cancer Epidemiol Biomarkers Prey. 2004; intake of animal fat. Domestic scholars have also found that the risk of ovarian cancer becomes higher with the intake of animal fat increased. ${ }^{[8]}$ The increased intake of egg cholesterol can also exacerbate the risk of ovarian cancer, $100 \mathrm{mg} / \mathrm{d}$ of egg cholesterol makes the probability reach up to $42 \%$. ${ }^{\text {[] }}$ Vegetable fat can improve the proportion of unsaturated fatty acid to saturated fatty acid, and increase the concentration of micronutrients, such as vitamin E, antioxidants. ${ }^{[10]}$

In summary, the incidence of ovarian cancer is closely associated with dietary factors. It is advocated to make a reasonable and healthy diet combination and develop a good eating habit, which contributes to the prevention of diseases. Since the number of samples is small, and influence factors may interact with each other, it is recommended to make a largescale survey for a more scientific evidence.

\section{Conflicts of Interest Disclosure}

The authors have no conflicts of interest related to this article.

13(9): 1521-1527. PMid: 15342455.

[6] Rose DP, Boyar AP, Wynder EL, et al. International comparisons of mortality rates for cancer of the breast ovary prostate and colon and percapita food consumption. Cancer. 198; 58(11): 2361-2371.

[7] Armstrong B, Doll B. Environmental factors and cancer incidence and mortality in different countries, with special reference to dietary practices. Int J Cancer. 1975; 15: 617. PMid: 1140864. https://doi.org/10.1002/ijc.2910150411

[8] Zhang M, Yang ZY, Binns CW, et al. Diet and ovarian cancer risk: a case study in China. Br J Cancer. 2002; 96(6): 911. https: //doi.org/10.1038/sj.bjc.6600085

[9] Gao YL, Kong BH. The prevention of ovarian carcinoma. Progress in Obstetrics and Gynecology. 2001; 10(2): 81.

[10] Bosetti C, Negri E, Franceschi S, et al. Olive oil, seed oils and other added fats in relation to ovarian cancer (Italy). Cancer Causes Control. 2002; 13(5): 465-470. PMid: 12146851. https://doi.org/ 10.1023/A: 1015760004130 